\title{
The Value of Insulin Degludec in Frail Older Adults with Type 2 Diabetes
}

\author{
W. David Strain (D) A Angharad R. Morgan · Marc Evans
}

Received: September 3, 2021 / Accepted: September 21, 2021 / Published online: October 4, 2021

(c) The Author(s) 2021

\begin{abstract}
Insulin represents a mainstay of glucose-lowering therapy for many adults with type 2 diabetes mellitus (T2DM). Insulin treatments prescribed as standard care for the majority of people with T2DM, such as basal human insulin, may not be optimal in the treatment of frail older adults because of the increased demand on health care staff to administer multiple daily injections and monitor the patient. When choosing an insulin regimen for a frail older person with T2DM, predictability of glucose lowering effect, risk of hypoglycaemia, ease of administration, and simplicity and flexibility of dosing are major determining factors. Multiple daily injections may be too complex for older frail adults, whilst providing an unnecessary degree of tight glycaemic control and low doses of once-daily basal insulin analogues such as
\end{abstract}

W. D. Strain $(\bowtie)$

Diabetes and Vascular Research Centre, University of Exeter Medical School, and the Academic

Department of Healthcare for Older Adults, Royal

Devon \& Exeter Hospital, Exeter, UK

e-mail: d.strain@exeter.ac.uk

A. R. Morgan

Health Economics and Outcomes Research Ltd., Cardiff, UK

M. Evans

Diabetes Resource Centre, University Hospital

Llandough, Cardiff, UK insulin degludec may be a reasonable option as cognitive decline or functional disability increases. Although insulin degludec has a substantially higher acquisition cost than routinely used basal human insulin, it has a longer, more predictable pharmacological profile and is more amenable to once-daily administration, translating into a reduced burden of care and potential cost savings for insulin-treated frail older adults. Insulin acquisition cost represents only a small proportion of the total cost of treatment, and it is important to consider the value perspective of insulin therapy in frail older adults from all stakeholders in the health care system.

Keywords: Frail elderly; Health care costs; Human insulin; Insulin analogue; Insulin degludec; Type 2 diabetes mellitus 


\section{Key Summary Points}

There are several different insulin treatment options for type 2 diabetes in older adults; however, current available treatment strategies are derived from findings in younger adults that do not commonly present with the issues associated with frailty and age, such as cognitive impairment and the presence of physical disabilities.

The presence of frailty, functional impairments, and cognitive decline in older adults with type 2 diabetes highlights the importance of community nursing support for insulin administration.

The protracted duration of insulin degludec facilitates flexible dosing and convenience with once-daily administration, translating into clinical and economic value, particularly in frail older adults.

Although insulin degludec has a substantially higher acquisition cost than basal human insulin, when considering the value of insulin, it is important to include insulin resource use beyond acquisition costs and, in particular, potential health care service use.

\section{INTRODUCTION}

Type 2 diabetes mellitus (T2DM) represents a major health burden for older adults, with prevalence increasing with age (Fig. 1). It affects one in five people $>65$ years old (135.6 million people worldwide) [1], and this number is expected to increase dramatically in the future with the global burden of T2DM in individuals $\geq 65$ years projected to reach 276.2 million by 2045 [1]. In addition to the usual complications of diabetes, the older population with diabetes also has a higher risk of other conditions such as falls and fractures, depression, physical disability, pain, polypharmacy due to co-morbidities, and urinary incontinence (Fig. 2). Therefore, the management of diabetes in these older adults demands different treatment strategies dependent on the presence or absence of comorbidities as well as on the patients' living situation and available resources.

Whilst the majority of older adults with T2DM are high functioning, medically stable, and able to perform self-care, diabetes can reduce physical functioning [2]. Sarcopenia (age-related muscle loss associated with reduced power) is a newly emerging and high-impact complication of T2DM in older adults $[3,4]$, with a prevalence in the range of $7-29 \%$ in different populations [5]. Sarcopenia leads to frailty, a condition in which an individual has decreased physical reserves [6], and is usually defined based on the presence of three or more of the following: unintentional weight loss, selfreported exhaustion, weakness, slow walking speed, and low physical activity [7]. Furthermore, T2DM has been consistently associated with an increased risk of cognitive decline, including Alzheimer's disease and vascular dementia [8-10], and compared to people without diabetes, individuals with diabetes have a greater rate of cognitive decline [11]. As the decline in cognitive function continues, older people with diabetes and dementia are

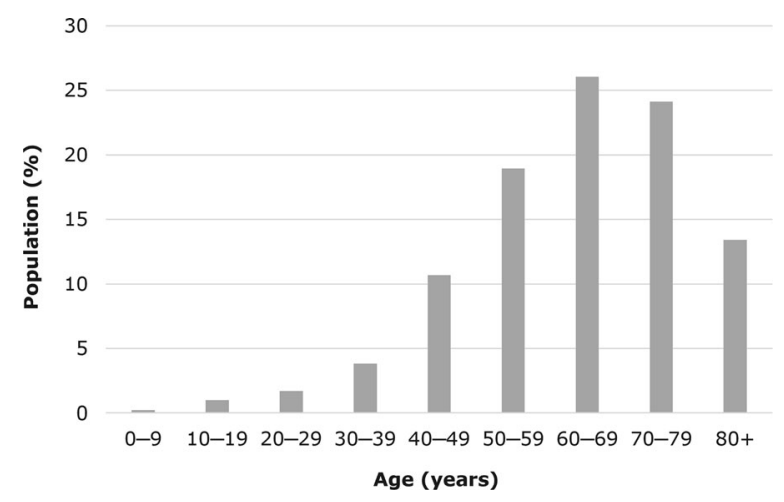

Fig. 1 Prevalence of diabetes by age group in England and Wales [44] 


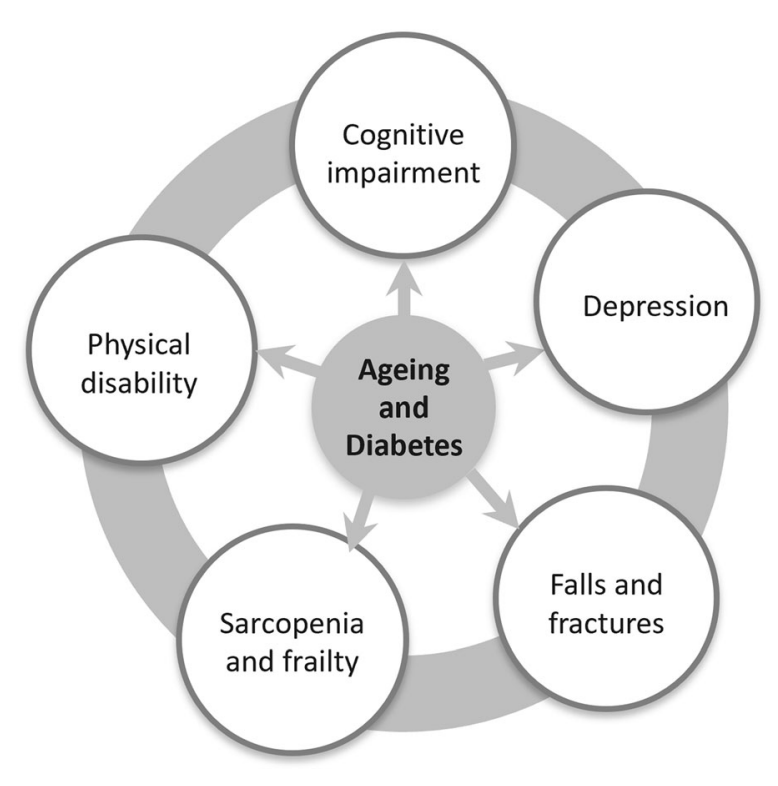

Fig. 2 Comorbidities in older adults with diabetes

liable to struggle to follow complex treatment regimens. The consequences of a mistake in selfmedication of diabetes treatments can be devastating; missed doses can result in a hyperosmolar hyperglycaemic state, or diabetic ketoacidosis in those with insulin deficiency, whereas excess dosing can lead to devastating hypoglycaemia. As a result, when cognitive decline ensues, these individuals often require considerable support from both health care and social care practitioners in diabetes management, including treatment administration. Consequently, the treatment of T2DM and its complications in older adults represents a significant cost to the NHS with approximately $61 \%$ of all health care costs attributed to T2DM being incurred by people with T2DM who are $>$ 65 years of age [12]. With this in mind, it is imperative to optimise the clinical and economic value with respect to treatment regimens in the population of frail older adults with T2DM.

This article is based on previously conducted studies and does not contain any studies with human participants or animals performed by any of the authors.

\section{INSULIN TREATMENT IN FRAIL OLDER ADULTS WITH T2DM}

T2DM treatments in frail older adults need to be carefully prescribed and monitored, taking into consideration the patient cognitive capacities, presence of other comorbidities, cardiovascular risk, and importance of avoiding hypoglycaemia. Although there are several different treatment options for older adults with T2DM, these treatment strategies are based on trial data in younger adults that do not commonly present with the issues associated with frailty and age. Despite the recommendations of international regulatory agencies to include a wide range of patients with T2DM, exclusion of older individuals from ongoing trials regarding T2DM is frequent [13]. This exclusion limits the level of evidence that clinicians require when treating frail older adults with T2DM. In the absence of clear clinical data, guidance is often based on expert consensus $[14,15]$.

Current treatment recommendations for frail older adults are limited to dipeptidyl peptidase4 (DPP-4) inhibitors, which have limited efficacy sodium-glucose co-transporter-2 (SGLT2) inhibitors for those with heart failure, and insulin [15]. Although there are many different approaches to insulin initiation, in many health care systems use of a basal insulin is the preferred approach to commencing insulin therapy in people with T2DM. The action profile of human basal insulin peaks within a few hours of administration, translating into a potential increased risk of hypoglycaemia, and in particular nocturnal hypoglycaemia if human insulin is administered in the evening. By contrast, insulin analogues provide slower, more prolonged absorption rates and a relatively constant pharmacokinetic/pharmacodynamic (PK/ PD) $24 \mathrm{~h}$ profile [16], reducing the potential of hypoglycaemia and furthermore offering the potential for more predictable once-daily dosing [17].

Insulin degludec is a basal insulin analogue with an ultra-long duration of action. This ultra-long duration of action, as well as the low variability in glucose-lowering activity of insulin degludec, has translated into real clinical 
benefits, in particular a reduced risk of hypoglycaemic events $[18,19]$.

Furthermore, the pharmacokinetic profile and protracted half-life of insulin degludec render this insulin a truly once-daily insulin and enables the potential for flexible dosing with a time interval of between 8 and $40 \mathrm{~h}$ without comprising its efficacy or safety profile. This dosing flexibility is particularly relevant when considering frail older adults that require assistance with insulin administration from a health care worker, carer, or relative. Consequently, even though there are limited data related to insulin degludec, or indeed any insulin, in frail older adults, the pharmacokinetic profile, greater convenience, and less variable glycaemic control render insulin degludec a very appealing therapy option for insulin administration in frail older adults.

\section{CLINICAL EFFICACY OF INSULIN DEGLUDEC FOR TREATING FRAIL OLDER ADULTS WITH T2DM}

The ultra-long-acting insulin degludec with reduced intra- and inter-individual variability in time-action profiles compared with other insulins can provide a more stable glucose-lowering action and improved PK/PD profile, which translates clinically into a reduced risk of hypoglycaemia [20]. Reduced risks of hypoglycaemia have been observed with insulin degludec across age groups including older adults. The results of a meta-analysis of pooled patientlevel data in older adults $\geq 65$ years from five BEGIN trials involving patients with T2DM $[18,19,21-23]$ demonstrated $24 \%$ and $36 \%$ lower estimated rates of overall hypoglycaemia and nocturnal hypoglycaemia, respectively, with insulin degludec compared to insulin glargine [24]. The hypoglycaemic benefits demonstrated with insulin degludec in older adults were consistent with those seen in the full adult patient population [25]. A post hoc analysis of data from the SWITCH 2 trial demonstrated that treatment with insulin degludec lowered the rates of overall severe and blood glucose-confirmed symptomatic hypoglycaemia by $30 \%$ and $31 \%$ versus insulin glargine in individuals aged $>65$ years and $\leq 65$ years, respectively. The reduction in the rate of nocturnal symptomatic hypoglycaemia or blood glucose-confirmed symptomatic hypoglycaemia with insulin degludec versus insulin glargine was 41 and $43 \%$, respectively, in individuals aged $>65$ years and $\leq 65$ years [26]. The reduced risk of hypoglycaemia with insulin degludec compared to glargine across the age groups was consistent with post hoc analysis of data from the DEVOTE trial, which also demonstrated that patients randomised to insulin degludec had a lower risk of severe hypoglycaemia and nocturnal hypoglycaemia compared to those randomised to insulin glargine across age groups (50-64 and 65-74 years), although a non-significant trend was demonstrated in patients aged $\geq 75$ years [27]. In addition, the cardiovascular safety data of insulin degludec versus glargine were also observed across age groups [27], which is an important consideration for clinicians managing older adults with T2DM in clinical practice, since this category of patients typically has high cardiovascular risk.

The reduction in hypoglycaemia is particularly important for frail, older adults with T2DM as this population is more vulnerable to the occurrence and consequences of hypoglycaemia, with episodes of severe hypoglycaemia in this population having been associated with increased risk of cardiac autonomic dysfunction [28], falls [29, 30], and dementia [31] (a 26\% increase in the risk for developing dementia after a single event with 3 or more 'events' increases the risk of dementia by 96\% [31]). Moreover, hypoglycaemia awareness in frail older adults may be impaired, and as this population often live alone the consequences of hypoglycaemia can result in significant morbidity for this particular group of patients. 


\section{HEALTH ECONOMIC IMPACT OF INSULIN DEGLUDEC FOR TREATING FRAIL OLDER ADULTS WITH T2DM}

As the acquisition cost for insulin degludec is greater than that of human insulin, many people with T2DM are preferentially prescribed human insulin primarily based on price considerations. However, as people become increasingly frail, the potential limitations of basal human insulin are likely to become more apparent particularly with respect to administration, flexibility of dosing, predictability of the glucose-lowering effect, and risk of hypoglycaemia. The dangers of inappropriate administration and dosing along with the patient's ability to appropriately administer insulin are critical factors that require regular review and assessment.

As cognitive decline or functional disability increases, the burden of insulin delivery will typically pass on to a family member, carer, or nursing staff. Therefore, when considering treatment costs, health visitor costs should be taken into account. A recent report 'Behind closed doors? The hidden impact of diabetes in social care found that there are $>70,000$ people in the UK in a social care setting and the direct care costs of T2DM amount to approximately $£ 1.4$ billion, five times more than is spent on the drug treatment itself [32].

The introduction of updated clinical guidelines for managing T2DM, with less stringent glycaemic targets for frail older adults [33, 34], aims to limit the risk of hypoglycaemia. However, a reduced risk does not negate the burden of hypoglycaemia completely. Hypoglycaemia carries a large cost burden as a result of hospitalisation for severe episodes [35]. It has been demonstrated that the occurrence of hypoglycaemia in older adults is associated with a $36 \%$ increase in diabetes related expenditure [36]. Whilst some of this is in the direct cost of the hypoglycaemia, a significant proportion of this is based on the increased risk of complications such as stroke, fractures, and increased use of social care [37]. Even non-severe hypoglycaemia can have economic consequences in older patients as they lose confidence and have increased dependency on social support [38]. Insulin analogues, with a low risk of hypoglycaemia, may be preferred in frail older adults with T2DM, as the drug acquisition cost has the potential to be offset by the cost saving from reduced hypoglycaemia-related health care resource utilisation.

Insulin regimens tend to be either a once- or twice-daily basal insulin. The latter requires administration with morning and evening meals within a relatively narrow time window. Staffing for the community nursing team can be a challenge with the team's core hours between $8 \mathrm{a} . \mathrm{m}$. and $6 \mathrm{p} . \mathrm{m}$. and there being a high demand for insulin administration around the start and finish of these core hours. This poses two challenges, the first is the logistics of administering the insulin within a short time window and the second is the cost of the visit itself in the setting of limited staffing. This has been exacerbated throughout the Covid-19 pandemic when community staff have been redeployed and the concerns regarding footfall and risk of coronavirus spread. Given that the NHS is currently facing a shortage of resources, in terms of both costs and the availability of health care workers to deliver this care, it is vital to evaluate the economic value, alongside the clinical efficacy, of different treatment regimens, such as insulin degludec, in frail older adults with T2DM.

In a UK health care setting, whereby district nurses in the community met regularly to review the diabetes patients they attend for insulin injections and where clinically appropriate, based mainly but not wholly on frailty status, a switch from twice- to a once-daily insulin regimen was implemented; the daily visit rate was reduced from 300 to 166 visits (23 patients had their insulin stopped and 121 switched to a once-daily insulin regimen) [39]. Although the cost saving associated with this initiative has not been reported, a reduction of 134 visits per day, 365 days per year, is likely to equate to a huge cost reduction.

Insulin degludec has a substantially higher acquisition cost ( $£ 46.60$ a month) than routinely used basal human insulin (i.e., Insulatard, Humulin; £19.08 per month) [40, 41]. However, 
due to its pharmacological profile, patients using insulin degludec would only require a maximum of one nurse visit per day compared to patients prescribed human insulin, which are likely to require multiple visits to ensure safe and optimal insulin dosing, administration, and monitoring. Furthermore, the biological stability when administered from 8 to $40 \mathrm{~h}$ apart increases the flexibility of administration [42], a notable advantage at times of stress on service, such as weekends, holidays, and times of significant staff pressure such as the Covid-19 pandemic. Consequently, the use of a more expensive, longer acting insulin that requires less monitoring and administration may ultimately translate into whole health care system cost savings when the cost of external assistance in included (Fig. 3). As the current NHS tariff for a nurse visit is $£ 30$ (based on a 15 -min visit for a band 7 nurse) [43], costs would be expected to be approximately $£ 900$ per month (30-day month) for degludec visits (once a day) and $£ 1800$ per month for human insulin visits (twice a day). Consequently, the estimated cost per month including drug acquisition cost and treatment administration is $£ 946.60$ for insulin degludec compared to $£ 1819.08$ for human insulin, resulting in a saving of $£ 872.48$ per patient per month $(£ 10,469.76$ per year) associated with nursing visits alone (in addition to the use of fewer needles and test strips).

\section{SUMMARY}

Insulin remains an important cornerstone of diabetes management for many frail older adults with T2DM. Age-related cognitive impairment and the presence of physical disabilities and other age-related problems, such as frailty, malnutrition, pain, and depression, may adversely affect self-care abilities, particularly around insulin administration, in older frail adults with T2DM. Consequently, there has been significant unmet need with respect to insulin therapy in this population. The requirement for the simplification of insulin regimens has been further highlighted over the past 18 months as a consequence of the Covid19 pandemic and the consequent stress this has

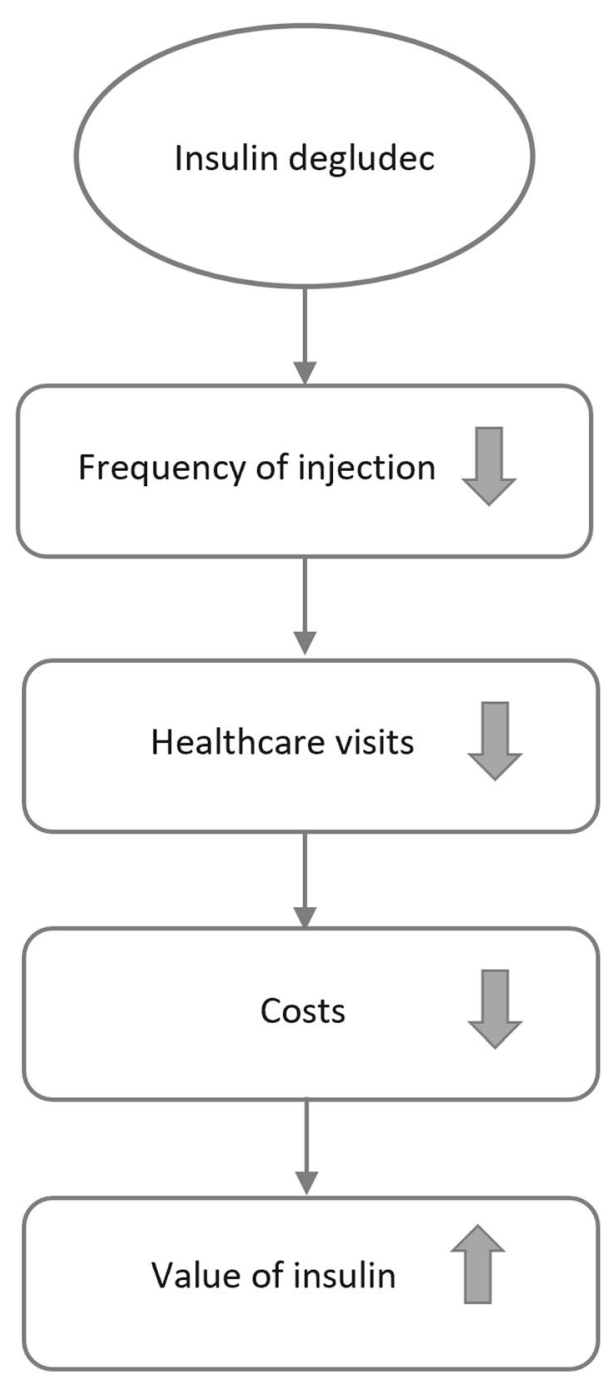

Fig. 3 Value of insulin degludec

placed on all stakeholders in the health care system including patients, carers, and community-based services. There has become a need to re-evaluate the insulin regimens of people who require district nursing visits for insulin administration to reduce contact and therefore reduce risk of contamination as well as to address the ever-increasing demand for community nursing services.

Insulin degludec represents a significant evolution with respect to insulin therapy in frail older adults, with the potential for flexible true once daily dosing that has obvious service resource utilisation impacts as well as quality of 
life benefits for patients as well as their family members and carers.

It is important to consider value of any therapy from a multiple stakeholder perspective, and while insulin degludec may have a higher acquisition cost compared to basal human insulin, it has a longer, more predictable pharmacological profile and is more amenable to once-daily administration, consequently reducing the burden of care and thus cost associated with supported insulin administration. Consequently, from both a clinical and health economic perspective, insulin degludec could be considered the basal insulin of choice in frail older adults with T2DM.

\section{ACKNOWLEDGEMENTS}

Funding. Sponsorship for this publication and the journal's Rapid Service Fee were funded by Novo Nordisk. The authors are grateful to Jayme Patel and Vasileios Antavalis of Novo Nordisk for providing a medical and health economic accuracy review of the outline and final draft.

Authorship. All authors meet the International Committee of Medical Journal Editors (ICMJE) criteria for authorship for this article, take responsibility for the integrity of the work, and have given their approval for this version to be published.

Authors' Contributions. W. David Strain, Angharad R. Morgan, and Marc Evans contributed to the study conception, drafting and revision of the manuscript.

Disclosures. W. David Strain has received unrestricted educational grants and speaker fees from AstraZeneca, Bayer, Boehringer Ingelheim, Eli-Lily, Novartis, Novo-Nordisk, and Takeda outside the submitted work and is supported by the NIHR Exeter Clinical Research Facility and the NIHR Collaboration for Leadership in Applied Health Research and Care (CLAHRC) for the South West Peninsula. The views expressed in this publication are those of the author(s) and not necessarily those of the NIHR Exeter Clinical Research Facility, the NHS, the NIHR or the Department of Health in England. Angharad R. Morgan is an employee of Health Economics and Outcomes Research Ltd., Cardiff, UK. Health Economics and Outcomes Research Ltd. received fees from Novo Nordisk in relation to medical writing support of this study. Marc Evans has received honoraria from AstraZeneca, Novo-Nordisk, Takeda and NAPP, and research support from NovoNordisk outside the submitted work, and has received financial support for consultancy from Novartis, Merck Sharp \& Dohme Corp. and Novo Nordisk, and has served on the speaker's bureau for Novartis, Lilly, Boehringer lngelheim, Merck Sharp \& Dohme Corp., Novo Nordisk, Janssen and Takeda. Marc Evans is also the Editor-in-Chief of Diabetes Therapy.

Compliance with Ethics Guidelines. This article is based on previously conducted studies and does not contain any studies with human participants or animals performed by any of the authors.

Data Availability. Data sharing is not applicable to this article as no datasets were generated or analysed during the current study.

Open Access. This article is licensed under a Creative Commons Attribution-NonCommercial 4.0 International License, which permits any non-commercial use, sharing, adaptation, distribution and reproduction in any medium or format, as long as you give appropriate credit to the original author(s) and the source, provide a link to the Creative Commons licence, and indicate if changes were made. The images or other third party material in this article are included in the article's Creative Commons licence, unless indicated otherwise in a credit line to the material. If material is not included in the article's Creative Commons licence and your intended use is not permitted by statutory regulation or exceeds the permitted use, you will need to obtain permission directly from the copyright holder. To view a copy of this licence, visit http://creativecommons.org/licenses/by$\mathrm{nc} / 4.0 /$. 


\section{REFERENCES}

1. International Diabetes Federation. IDF diabetes atlas 9th edition. 2019. https://www.diabetesatlas. org/en/. Accessed 5 July 2021.

2. Wong E, Backholer K, Gearon E, Harding J, FreakPoli R, Stevenson C, et al. Diabetes and risk of physical disability in adults: a systematic review and meta-analysis. Lancet Diabetes Endocrinol. 2013;1(2):106-14.

3. Sinclair A, Morley J. Frailty and diabetes. Lancet. 2013;382(9902):1386-7.

4. Sinclair AJ, Abdelhafiz AH, Rodríguez-Mañas L. Frailty and sarcopenia - newly emerging and high impact complications of diabetes. J Diabetes Complicat. 2017;31(9):1465-73.

5. Izzo A, Massimino E, Riccardi G, Della PG. A narrative review on sarcopenia in type 2 diabetes mellitus: prevalence and associated factors. Nutrients. $2021 ; 13(1): 183$.

6. Satake S, Arai H. Chapter 1 frailty: definition, diagnosis, epidemiology. Geriatr Gerontol Int. 2020;20 Suppl 1:7-13.

7. Fried LP, Tangen CM, Walston J, Newman AB, Hirsch C, Gottdiener J, et al. Frailty in older adults: evidence for a phenotype. J Gerontol A Biol Sci Med Sci. 2001;56(3):M146-56.

8. Strachan MW, Deary IJ, Ewing FM, Frier BM. Is type II diabetes associated with an increased risk of cognitive dysfunction? A critical review of published studies. Diabetes Care. 1997;20(3):438-45.

9. Hassing LB, Grant MD, Hofer SM, Pedersen NL, Nilsson SE, Berg S, et al. Type 2 diabetes mellitus contributes to cognitive decline in old age: a longitudinal population-based study. J Int Neuropsychol Soc. 2004;10(4):599-607.

10. Yaffe K, Blackwell T, Kanaya AM, Davidowitz N, Barrett-Connor E, Krueger K. Diabetes, impaired fasting glucose, and development of cognitive impairment in older women. Neurology. 2004;63(4):658-63.

11. Cukierman T, Gerstein HC, Williamson JD. Cognitive decline and dementia in diabetes-systematic overview of prospective observational studies. Diabetologia. 2005;48(12):2460-9.

12. American Diabetes Association. Economic Costs of Diabetes in the US in 2017. Diabetes Care. 2018;41(5):917-28.
13. Cruz-Jentoft AJ, Carpena-Ruiz M, Montero-Errasquín B, Sánchez-Castellano C, Sánchez-García E. Exclusion of older adults from ongoing clinical trials about type 2 diabetes mellitus. J Am Geriatr Soc. 2013;61(5):734-8.

14. Strain WD, Hope SV, Green A, Kar P, Valabhji J, Sinclair AJ. Type 2 diabetes mellitus in older people: a brief statement of key principles of modern day management including the assessment of frailty. A national collaborative stakeholder initiative. Diabet Med. 2018;35(7):838-45.

15. Strain WD, Down S, Brown P, Puttanna A, Sinclair A. Diabetes and frailty: an expert consensus statement on the management of older adults with type 2 diabetes. Diabetes Ther. 2021;12(5):1227-47.

16. Evans M, Schumm-Draeger PM, Vora J, King AB. A review of modern insulin analogue pharmacokinetic and pharmacodynamic profiles in type 2 diabetes: improvements and limitations. Diabetes Obes Metab. 2011;13(8):677-84.

17. Rosenstock J, Dailey G, Massi-Benedetti M, Fritsche A, Lin Z, Salzman A. Reduced hypoglycemia risk with insulin glargine: a meta-analysis comparing insulin glargine with human NPH insulin in type 2 diabetes. Diabetes Care. 2005;28(4):950-5.

18. Garber AJ, King AB, Del Prato S, Sreenan S, Balci $\mathrm{MK}$, Muñoz-Torres $\mathrm{M}$, et al. Insulin degludec, an ultra-longacting basal insulin, versus insulin glargine in basal-bolus treatment with mealtime insulin aspart in type 2 diabetes (BEGIN Basal-Bolus Type 2): a phase 3 , randomised, open-label, treat-to-target non-inferiority trial. Lancet. 2012;379(9825): 1498-507.

19. Zinman B, Philis-Tsimikas A, Cariou B, Handelsman $\mathrm{Y}$, Rodbard HW, Johansen T, et al. Insulin degludec versus insulin glargine in insulin-naive patients with type 2 diabetes: a 1-year, randomized, treat-totarget trial (BEGIN Once Long). Diabetes Care. 2012;35(12):2464-71.

20. Haahr H, Heise T. A review of the pharmacological properties of insulin degludec and their clinical relevance. Clin Pharmacokinet. 2014;53(9): 787-800.

21. Meneghini L, Atkin SL, Gough SC, Raz I, Blonde L, Shestakova $M$, et al. The efficacy and safety of insulin degludec given in variable once-daily dosing intervals compared with insulin glargine and insulin degludec dosed at the same time daily: a 26-week, randomized, open-label, parallel-group, treat-to-target trial in individuals with type 2 diabetes. Diabetes Care. 2013;36(4):858-64.

22. Gough SC, Bhargava A, Jain R, Mersebach H, Rasmussen S, Bergenstal RM. Low-volume insulin 
degludec 200 units/ml once daily improves glycemic control similarly to insulin glargine with a low risk of hypoglycemia in insulin-naive patients with type 2 diabetes: a 26-week, randomized, controlled, multinational, treat-to-target trial: the BEGIN LOW VOLUME trial. Diabetes Care. 2013;36(9):2536-42.

23. Onishi Y, Iwamoto Y, Yoo SJ, Clauson P, Tamer SC, Park S. Insulin degludec compared with insulin glargine in insulin-naïve patients with type 2 diabetes: A 26-week, randomized, controlled, PanAsian, treat-to-target trial. J Diabetes Investig. 2013;4(6):605-12.

24. Sorli C, Warren M, Oyer D, Mersebach H, Johansen $\mathrm{T}$, Gough SC. Elderly patients with diabetes experience a lower rate of nocturnal hypoglycaemia with insulin degludec than with insulin glargine: a meta-analysis of phase IIIa trials. Drugs Aging. 2013;30(12):1009-18.

25. Ratner RE, Gough SC, Mathieu C, Del Prato S, Bode $\mathrm{B}$, Mersebach $\mathrm{H}$, et al. Hypoglycaemia risk with insulin degludec compared with insulin glargine in type 2 and type 1 diabetes: a pre-planned metaanalysis of phase 3 trials. Diabetes Obes Metab. 2013;15(2):175-84.

26. Heller SR, DeVries JH, Wysham C, Hansen CT, Hansen MV, Frier BM. Lower rates of hypoglycaemia in older individuals with type 2 diabetes using insulin degludec versus insulin glargine U100: results from SWITCH 2. Diabetes Obes Metab. 2019;21(7):1634-41.

27. Pratley RE, Emerson SS, Franek E, Gilbert MP, Marso SP, McGuire DK, et al. Cardiovascular safety and lower severe hypoglycaemia of insulin degludec versus insulin glargine U100 in patients with type 2 diabetes aged 65 years or older: results from DEVOTE (DEVOTE 7). Diabetes Obes Metab. 2019;21(7):1625-33.

28. Adler GK, Bonyhay I, Failing H, Waring E, Dotson S, Freeman R. Antecedent hypoglycemia impairs autonomic cardiovascular function: implications for rigorous glycemic control. Diabetes. 2009;58(2): 360-6.

29. Schwartz AV, Vittinghoff E, Sellmeyer DE, Feingold KR, de Rekeneire N, Strotmeyer ES, et al. Diabetesrelated complications, glycemic control, and falls in older adults. Diabetes Care. 2008;31(3):391-6.

30. Nelson JM, Dufraux K, Cook PF. The relationship between glycemic control and falls in older adults. J Am Geriatr Soc. 2007;55(12):2041-4.

31. Whitmer RA, Karter AJ, Yaffe K, Quesenberry CP Jr, Selby JV. Hypoglycemic episodes and risk of dementia in older patients with type 2 diabetes mellitus. JAMA. 2009;301(15):1565-72.

32. Institute of Diabetes for Older People and Novo Nordisk. Behind closed doors? The hidden impact of diabetes in social care 2013. http://diabetesfrail. org/wp-content/uploads/2015/07/Idop-behindclosed-doors.pdf. Accessed 5 July 2021.

33. American Diabetes Association. 12. Older adults: standards of medical care in diabetes-2019. Diabetes Care. 2019;42(Suppl 1):S139-47.

34. International Diabetes Federation. Global guideline for managing older people with type 2 diabetes 2017. https://www.idf.org/e-library/guidelines/78global-guideline-for-managing-older-people-withtype-2-diabetes.html. Accessed 5 July 2021.

35. Leese GP, Wang J, Broomhall J, Kelly P, Marsden A, Morrison W, et al. Frequency of severe hypoglycemia requiring emergency treatment in type 1 and type 2 diabetes: a population-based study of health service resource use. Diabetes Care. 2003;26(4):1176-80.

36. Johnston SS, Conner C, Aagren M, Ruiz K, Bouchard J. Association between hypoglycaemic events and fall-related fractures in Medicare-covered patients with type 2 diabetes. Diabetes Obes Metab. 2012;14(7):634-43.

37. Hammer M, Lammert M, Mejías SM, Kern W, Frier BM. Costs of managing severe hypoglycaemia in three European countries. J Med Econ. 2009;12(4): 281-90.

38. McCluskey L, Jagger O, Strain WD. Hypoglycemia associated with impaired mobility and diminished confidence in an elderly person with type 2 diabetes. Diabet Hypoglycemia. 2014;7(1):11-4.

39. Down S. Service update: the success of district nursing virtual clinics in Somerset. J Diabetes Nurs. 2019;23:JDN066.

40. National Institute for Health and Care Excellence. BNF: Insulin Degludec. https://bnf.nice.org.uk/ medicinal-forms/insulin-degludec.html. Accessed 5 July 2021.

41. National Institute for Health and Care Excellence. BNF: Isophane Insulin. https://bnf.nice.org.uk/ medicinal-forms/isophane-insulin.html. Accessed 5 July 2021.

42. European Medicines Agency. Tresiba (insulin degludec) summary of product characteristics 2021. https://www.ema.europa.eu/en/medicines/human/ EPAR/tresiba\#product-information-section. Accessed 5 July 2021. 
43. Personal Social Services Research Unit (PSSRU). Unit costs of health and social care 2020: II community-based health care staff 2020. https://www. pssru.ac.uk/project-pages/unit-costs/unit-costs2020/. Accessed 5 July 2021.
44. Diabetes UK. Diabetes: facts and stats 2014. https:// www.diabetes.org.uk/resources-s3/2017-11/ diabetes-key-stats-guidelines-april2014.pdf. Accessed 5 July 2021. 